\title{
How Homelessness Compromises the Exercise of the Rights of Citizenship in Australia
}

\author{
Emily Schindeler, Queensland University of Technology, Queensland, \\ Australia
}

\begin{abstract}
This paper is drawn from an analysis of the impact of the Australian Government's legal, policy and administrative frameworks on the ability of people who are homeless to access entitlements available to all Australian citizens. Despite a claim to legislative protections and anti discrimination statute, this examination reveals a history of exclusion in which the homeless have been denied equal access to such entitlements, dating from pre-federation through the twenty first century. It concludes by posing an alternative way of thinking that has the potential to reframe and redress the failure to protect and enable the exercise of such rights by those who are homeless.
\end{abstract}

Keywords: Citizenship, Discrimination, Homeless

\section{Citizenship, Human Rights and Social Inclusion Discourse}

$\mathrm{T}$

HERE IS A strong interplay between the discourse of citizenship, human rights and social inclusion. Each of these discourses is concerned with the ability of the individual and populations to exercise and enjoy an active part in social, economic and political life. This paper does not explore this broad scope of social, economic and political participation. It documents two ways in which the legal apparatus of Government has and continues to deny the rights of citizenship to those who are homelessness.

\section{The Law and the Machinery of Administration}

Both the law and the administrative machinery by which the law is implemented enable Government to exercise power over the individual. Rose explains this dimension of governing as "incorporating apparatus to deal with management at large scale and micro technologies for management of human conduct of individuals in particular locales and practices" (Rose $1999,5)^{1}$. It is through the practical actions of Government agencies that it is possible to view the exercise of power and its consequences.

Law has inherent within it the power of application and enforcement. It provides the authority to establish and demand compliance with particular ways of behaving and obligations, codifying them as part of the juridical system (Ewald 1990, 138-139) ${ }^{2}$. In this way the law establishes a basis for differentiating between the norm and abnormal and establishing compliance with behavioural norms as a duty rather than a choice. It is this power of discipline (in terms of individual compliance and the juridical power of enforcement) that effectively

\footnotetext{
${ }^{1}$ Rose, N. 1999. Powers of Freedom, Reframing Political Thought, Cambridge: Cambridge University Press.

${ }^{2}$ Ewald, F. 1990. Norms, Discipline and the Law, Representations 30, Spring 1990 University of California.
} 
produces and reproduces the standard by which individuals are judged. This in turn helps to define and reflect upon the worthiness of the individual.

\section{Citizenship}

Defining and granting citizenship operates as a technology through which the government makes visible its relationship with the population and the relationship between individuals and groups within the nation (Hindess, 2002, 128; Rubenstein, 2002, 5) ${ }^{3}$. Whereas a feudal system or monarchy is reliant on loyalty to the ruler, a system based upon citizenship defines the relationship of the individual to the state, with notions of equality, mutual obligation and rights (Heater 2003, 2) ${ }^{4}$.

Consequently, citizenship entails the dual facets of identity, the identity of the 'subject to' and that of 'individual rights and duties'. Citizenship involves the governing of others and governing of self and as such is a tool which brings together the individualising and integrating practices of government. This involves respect (for rules) and responsibility (to others) and in this way citizenship acts as a bridge between the exercise of power and the governing of the self (White and Hunt, 2000, 98)

Citizenship involves more than the notion of obligation to the state and to the exercise of the responsibilities that this entails. It also has embedded within it those characteristics which are tacitly if not explicitly ascribed to the 'good citizen'. The 'good citizen' from its earliest origins has been one who is self reliant, industrious, and self governing.

Modern concepts of citizenship are a direct legacy of the Greek and Roman antecedents, the era of revolutions in England, the United States and France, and from the writings of such notable proponents of citizen rights and obligations as John Locke and Jan Jacques Rousseau. Modern citizenship, that is post American and French revolutions, is described by Marshall (1950) ${ }^{6}$ and Hindess (2002) as encompassing civil rights, political rights, and social rights, which in totality refer to the ability of citizens to participate equally and unencumbered in the social, economic and political way of life available to all citizens of the state. Further, it is the obligation of the Government to ensure the social right of participation is not compromised because (due to) poverty, ill health or lack of education.

\section{Historical Perspective on the Defining Citizens in Australia}

The term citizen is not defined nor does it appear in the Australian Constitution. This is an outcome of a deliberate decision by the framers of the Constitution to exclude any definition or to ascribe any specific rights to citizenship, but rather to leave this to other legislative instruments.

Records of the 1891 and 1897-99 pre-federation constitutional convention debates highlight the ambiguity which surrounded the notion of citizenship, and the inherent acceptance of discrimination in the granting of the privileges of citizenship. Discrimination based on race

\footnotetext{
${ }^{3}$ Hindess, B. 2002. Neoliberal Citizenship, Citizenship Studies 6(2):127-143, Routledge Taylor and Francis Group. Rubenstein, K. 2002. Australian Citizenship Law in Context, Freemont NSW: Lawbook Co

${ }^{4}$ Heater, D. 1990. Citizenship: The Civic Ideal in World History, Politics and Education. U.K.: Longman.

${ }^{5}$ White, M. and A. Hunt. 2000. Citizenship: Care of the Self, Character and Personality, Citizenship Studies, 4(2):93- 116.

${ }^{6}$ Marshall, T. H. 1992. Citizenship and social class. Pluto Press, Concord, Mass.
} 
and nationality was not considered incompatible with the principles of citizenship for the majority of the delegates to such debates (Galligan and Roberts, 2004; Rubenstein, 2002) ${ }^{7}$.

Discrimination continued to be a contentious issue with little consensus about what distinction should be made between being members of the federation, the status of citizenship and franchise. The consequence of the decision not to address citizenship within the constitution was the deployment of the rights and entitlements of citizenship within a number of pieces of legislation and through the application of various administrative tools. It is this dispersion of legislative provisions, built on a foundation in which discrimination against specific members of the Australian community that enables people who are homeless to experience fewer rights than other citizens. It was not until the passage of the Australian Citizenship Act 1948 that the term 'citizen' first appeared in Australian legislation. It is for this reason that it is essential to examine the preceding legislation which allocated franchise rights and duties normally attributed to the status of citizen.

\section{National Franchise}

The right to participate in political processes, to be an elector, is embedded in the concept of membership in the Australian community, and a privilege of citizenship. Within the Australian context, voting is both an entitlement and civic duty. Denial of franchise is a denial of the constitutional commitment to the selection of the government by the people. It is for this reason that the rules and regulations which shape access to and determine the administration of the electoral processes form a foundational part of the political framework.

In debating the question of franchise, there was considerable disagreement amongst the $19^{\text {th }}$ century constitutional convention delegates about who had the required fitness to be allowed to vote. The fitness of women, Aboriginals, migrants of colour, those of 'unsound mind', offenders and the institutionalised poor were all subjects of controversy. Of particular import was the debate around disenfranchisement of the poor.

The right (and obligation) to participate in the political process through voting is set by legislation, and the mechanisms which dictate processes for exercising that right are situated in regulation and administrative practices. Although the first Commonwealth electoral legislation did not define or employ the term 'citizen', it set conditions associated with who and who was not eligible to participate in the electoral process.

The significance of franchise lies, however, beyond the ability to vote and participate in political processes. It also acts as a hurdle which must be cleared to access other entitlements or opportunities. For example, requisite proofs, including a residential address, form part of the minimum criteria and without which the individual is effectively disqualified. This includes individuals who within the terms of law should not be excluded from voting. This creates an administrative barrier to the exercise of (compulsory) participation, as well as limiting access to other entitlements for which being on the electoral roll has been (and is) a requirement as a demonstration of citizenship.

In April 1902, the Barton Government proposed to amend legislation to remove the voting rights of any person who was living in a charitable institution and reliant on such relief. The rationale was the assertion that people living in public charitable institutions would be so "withdrawn absolutely from contact with ordinary life and public affairs [and] should not

\footnotetext{
${ }^{7}$ Galligan, B. and W. Roberts. 2004. Australian citizenship. Carlton, Victoria: Melbourne University Press.
} 
be in a position to exercise full political rights" (Norberry and Williams 2002, 39.). The amendment was rejected, despite garnering some support, not because it was discriminatory against the poor, but rather because it had no precedence upon which to justify it.

The Commonwealth Franchise Act 1902 and Commonwealth Electoral Act 1902 then set the essential qualifications to vote, and the grounds for exclusion. The Commonwealth Franchise Act 1902 articulated eligibility qualifications including a place of permanent residence and inclusion in the electoral roll. Those denied the right to franchise included any person considered to be of unsound mind, who had committed treason or been convicted and sentenced of imprisonment one year or longer, all Australian Indigenous peoples, any person from Asia, Africa or the Pacific Islands (except New Zealand). Discrimination against and disenfranchisement of groups of people were accepted as a desirable and embedded in the law.

It was the Commonwealth Electoral Act 1918 that provided the nuts and bolts for the administration of voting within Australia. Although amendments have enabled a more universal voting system, as well as introducing greater regulation of voting arrangements, the changes did not remove the regulatory barriers to participation by people who are homeless (Joint Standing Committee, 2003) ${ }^{8}$.

The first major review of the Act was undertaken in 1983 by the Joint Select Committee on Electoral Reform. One outcome of this review was the creation of an itinerant voter classification for any individual temporary living away from their 'real place of living' and to which they have an intention to return. People who were homeless were tacitly excluded from this option as they did not have a 'real place of living' to which to return.

In reviewing the 2001 post election submissions to the Joint Select Committee on Electoral Reform, attention was drawn to the disenfranchisement of people who are homeless as a consequence of the Act and its regulations. The Committee recommended that the itinerant elector provisions be amended to make clear that this arrangement was also available to people who are homeless. Further, it recommended that the Australian Electoral Commission (AEC) simplify the application form to ensure its applicability to those who are experiencing homelessness. The AEC was also charged with undertaking a more proactive approach to community education and promotion of this entitlement through relevant agencies as well as the general public (Joint Select Committee Report 2003, 17).

Following the February 2004 federal election, the Joint Select Committee was again asked to consider the barriers to participation by people who are homeless. Submissions to the Committee highlighted the failure to make explicit within the Commonwealth Electoral Act 1918 the application of the Itinerant provisions for people who are homeless. It was further argued that proposed amendments to the Act would exacerbate the disenfranchisement of those experiencing homelessness. These amendments included requirements for identification, residency and changes in the timing for enrolment. The practical implications of such administrative changes on the homeless were explained as follows:

Identification The proposed (and subsequently legislated) proof of identity requirements demand three means of proof, that is a driver's license, written references by prescribed persons, or two references by people who have known the applicant for more than one month and is an enrolled Ordinary Elector. Collectively, and individually, each of these requirements

\footnotetext{
${ }^{8}$ Joint Standing Committee on Electoral Matters, Parliament of Australia. 2003. Report of the Inquiry into the 2001 Federal Election and matters related thereto.
} 
is not easily met by people who are homeless. It is unlikely that many homeless people would have a driver's license or surrogate forms of identification. It was also argued that there would be a reticence amongst many homeless people to approach prescribed persons such as police, lawyers or justices of the peace particularly when the individual may have had a negative experience with the legal system. Obtaining two people who are currently enrolled as Ordinary Electors and who have known the person for the specified period was also seen as a significant hurdle for many people who have been homeless. The impact then of these administrative arrangements was to effectively act as a disincentive if not an actual obstacle to enrolment.

Residency Requirements The itinerant provisions do not apply to anyone who has a fixed place of residency for longer than one month. This is creates a significant barrier to enrolment given that a number of supported accommodation services and refuges have a 6 or 13 week crisis accommodation period. However, this was not taken into account within the Act or its regulation. Whether accommodated in a refuge or other emergency accommodation arrangement after one month the individual is no longer eligible as an itinerant voter. In the absence of any permanent address, anyone who is homeless remains unable to enroll as an ordinary elector.

Conditions of Enrolment The amendment of the Act which provides for closure of the electoral roll on the day in which a writ of election is issued again disadvantages those who are homeless. Of particular risk is that even if an individual has been enrolled, if a previous permanent address has lapsed then the person will have been removed from the roll. Equally, it is likely that in the process of getting through the essentials of survival that a person who is homeless may not be aware of the issue of a writ or be aware in sufficient advance that an election is likely to be called.

Following the 2007 Federal Election, the terms of reference for the Inquiry by the Senate Committee did not incorporate responsibility for review of the implementation of previous post election recommendations intended to actively assist people who are homeless to enroll and vote. Nonetheless, the Public Interest Law Clearing House (PILCH) told the Inquiry that significant barriers remained. In making its submission, PILCH highlighted that the Australian Electoral Commission (AEC) had failed in its obligation to provide user friendly materials to enable enrolling as a 'no fixed address' voter. Similarly the AEC had not adequately implemented an action plan to raise awareness of the right to vote, nor provided any facility to assist enrolment by people who are homeless. PILCH also criticized the failure to make it explicit within the Electoral Act that the provision for itinerant voters applies in the same way to people who are homeless 9 .

Provision and targeted dissemination of information by the AEC needs to be appreciated in the environment in which there are a number of the disincentives to enrolment. The Swinburne University study of voting preferences of people who were homeless which found that $64 \%$ of respondents had indicated that they would like to vote but had not done so being unaware of how to enroll and / or feared that they would receive a fine for a failure to vote (AEC 2005, 9). Similarly, the PILCH consultation with homeless people in March 2005 found people reported the same barriers to participation as well as a belief that they were

\footnotetext{
${ }^{9}$ Public Interest Law Clearinghouse. 2008. Homelessness and Voting, Submission to the Joint Standing Committee on Electoral Matters, Inquiry into the 2007 Federal Senate Finance and Public Administration Committee. 1998. Report on the provisions of the electoral and referendum amendment bill (No. 2) 1998.
} 
ineligible to vote and concern about the consequences of having their name on an electoral roll. ${ }^{10}$ Although the AEC largely discounted the argument of structural barriers to participation, and preferred to emphasize what they termed 'social' issues, it was clear that lack of participation in the political process was not an abdication of or indication of any wish not to vote.

The statutory and administrative arrangements have regulated out the right to political participation and an effective denial of franchise. Unable to exercise this duty, or take advantage of this right, the constitutional intention that the government be selected by the people is not realized. Further the administrative rules and regulations continue to perpetuate this discrimination.

\section{Legislating Individual Rights}

Unlike the majority of Australia's western counterparts and an increasing number of the world's nation states, Australia has no legal instrument articulating the nature of, or a commitment to, individual rights.

The Australian Constitution contains neither a bill of rights nor any other legally binding charter of individual rights. Although there is national anti discrimination legislation, any right which may be granted by an Act of Parliament can also be reversed by Parliament, thereby limiting such statutory provisions to the status of virtual entitlements rather than enduring rights.

In the absence of any legislated guarantee of social, civil and economic rights, successive Australian governments have been able to justify and promote active discrimination amongst its own citizens. This is best illustrated by the discretionary way in which income support is made available. Although the basis for, and reasoning behind the way in which government assistance has been distributed has been varied by different governments, it has remained an act of Government beneficence rather than obligation.

Despite a number of efforts to promote the establishment of a constitutional recognition of rights, this has failed to attract sufficient traction from the electorate. In 1973 Attorney General Lionel Murphy introduced a Human Rights Bill, the main aim of which was to implement the United Nations International Covenant on Civil and Political Rights. The Bill was not supported and lapsed with the dismissal of the Whitlam Government in November 1974. A decade later, a draft bill of rights was prepared under the leadership of the Attorney General Gareth Evans. This version was limited to Government actions rather than the broader application of its predecessor. However it never reached the floor of Parliament. In 1985 the Attorney General, Lionel Bowen introduced to Parliament a redrafted Bill which was substantially weaker than those presented by either Murphy or Evans. The failure of the Bill to pass through the Senate resulted in its withdrawal. In speaking against the Bill, senators from the Opposition, both National and Liberal Parties, offered quite contradictory criticisms of the legislation - from its ability to impact on states' rights, to the lack of application to states, to the need for greater protections, to the need for no further protections than accorded by the Constitution.

Following the failure to achieve legislative change, Prime Minister Hawke convened a public referendum seeking the consent of the people to amend the Constitution to incorporate

\footnotetext{
${ }^{10}$ This included people who had experienced domestic violence for example.
} 
basic rights to trial by jury, to extend freedom of religion, and to ensure fair terms for persons whose property is acquired by any government. The referendum failed with less than $30 \%$ of the popular vote supporting change.

Given the failure to achieve either political or public support for amendment to the Constitution, the primary legislation in which legal obligations for human rights are articulated is the Human Rights and Equal Opportunity Commission Act (HREOC). HREOC is also responsible for oversight of the Age Discrimination Act 2004, Disability Discrimination Act 1992, Racial Discrimination Act 1975 and Sex Discrimination Act 1984. Importantly, none of these Acts lay the foundation for positive rights but rather are limited to offering protection against specific forms of discrimination and in certain circumstances rather than discrimination in general. By addressing discrimination through individual complaint, the law has the force of atomising discrimination and in this way becomes a means of control rather than a guarantee of rights. A corollary to this is the lack of any prohibition under existing legislation, which makes it unlawful to discriminate on the basis of social or economic status.

Not only have successive national governments avoided incorporating citizenship entitlements within legislation; they have also failed to take positive action to ensure such rights are attainable by the population as a whole.

\section{Political Rationalities, Poverty, and Access to Income Support}

Proponents of action to address the needs of the homeless, and those experiencing the extremes of poverty more broadly, have historically relied upon a measure of relative need as the basis for argument. However over the last decade social, legal and community advocates have adopted the rhetoric of human rights as the basis of argument (Sackville 2004; Lynch and Cole 2007; Otto 2002). ${ }^{11}$ Critically, the failure to respond to either argument, has not, and is not, simply a matter of resources or expenditure. There are significant economic, social and political values that have shaped the way the Australian Government has chosen to interpret these obligations. It is the philosophic and political rationalities of Australian Governments that have created a fundamental schism between the principles of equity and the delivery of citizen rights.

Poverty is arguably a primary factor in homelessness. Despite the myriad of literature linking homelessness with social, personal and economic factors, those living in poverty cannot afford the basics, including housing. Poverty involves more than financial disadvantage just as homelessness involves more than lacking shelter. Homelessness impacts on the realisation of many other rights, access to public education and to support entitlements available to those who are housed. Failure to address poverty renders the homeless marginalised from entitlements for which they would otherwise be entitled.

Article 9 of the International Covenant on Economic, Social and Cultural Rights, to which Australia is a signatory, establishes the right to social security through the provision of the means to acquire basic resources where individuals are unable to do so themselves. From a practical perspective, the Australian Government's interpretation of its responsibilities in responding to poverty (and its corollary homelessness) has been based on a belief in the

\footnotetext{
${ }^{11}$ Sackville, R. 2004. Homelessness, human rights and the law, Australian Journal of Human Rights, 10(2). Lynch, P. and J. Cole. 2003. Homelessness and Human Rights: Regarding and Responding to Homelessness as a Human Rights Violation. Melbourne Journal of International Law 4 (1): 139-76; Otto, ibid
} 
primacy of the individual as a self governing citizen, responsible for his/her own conduct and for ensuring that such conduct is consistent with the social and economic norms of independence.

As a consequence income support has never been viewed as a right, but rather as a privilege and subject to the vagaries of changing governments. Income support has been and remains available only to those considered deserving. Rigorous assessment criteria determine eligibility and create a gateway through which individuals must pass. Inadequate income, poverty and homelessness, are not themselves sufficient to obtain assistance.

Failure to achieve personal autonomy (as evidenced by the conception of an individualised poverty) is a failure of the individual and should not be rewarded. Remedial action (education and training) or authoritarian regulation ('mutual obligation' requirements) are required. The former is intended to compensate for the deficiency of the individual to work effectively in the open market, and the latter to ingrain good habits. The aim of such techniques of Government is to establish rules, mechanisms and processes that are founded upon the logic of discipline and rehabilitation.

Although there was considerable argument about how to approach welfare programs during the 1920's and 1930's, it was the depression of the 1930's that led the Government to offer financial support to the unemployed. Over the next two decades there was little change to the welfare system given relatively high employment and general social stability. However, the Fraser Government reshaped the income support program. Failing a work test, and bringing in new conditions for eligibility for assistance, such as the establishment of waiting periods prior for any support for school leavers, further disadvantaged the homeless and those living in poverty.

The first major review of the welfare system in 1986 continued the focus on 'active assistance' with a growing number of compulsory requirements such as personal lodgement of fortnightly income and work search effort forms, completion of a work intention questionnaire, and compulsory interviews. Some two years later, requirements were increased demanding intensive interviews, tougher work search requirements and referral to training and labour market programs.

A second major review in 1999, known as the McClure Report, was released in 2000. As with its predecessors, the target for reform lay in strategies for encouraging workforce participation and strengthening the requirements of mutual obligation. The recommendations focused on increasing incentives to work. Although the review acknowledged the impact of structural changes in employment, the terms of reference precluded any consideration of how such issues should/could be addressed.

Each of these successive changes to the income support system entailed increasingly rigorous requirements that made it very difficult for the homeless to achieve compliance. With little regard to the disadvantage experienced by the homeless, the regulation of income support further punished the disadvantaged. With Government administrative communication being directed solely through the mail, anyone lacking a postal address, that is the homeless, were unable to receive any notifications. The inability to generate the extensive identification requirements or to attend any regular training give the challenge of day to day survival, has meant that the homeless were subject to regular breaching and a consequent loss of any financial assistance. 
It is these regulatory tools that reflect the authoritarian nature of government assistance, acting as effective punishment for the failing individual. This ensured that income support was no longer a social and economic safety net.

Those who are homeless and living in poverty are the least likely to be able to access income support. Regulation and administrative practices establish a barrier which cannot be cleared by those struggling for survival day by day. Most importantly, as with political franchise, income support remains subject to discriminatory practices that preclude access or equity.

It is possible then to infer that the problem perceived by Government lies solely in the economic arena. Given the lack of acknowledgement of either social or systemic disadvantage, poverty and homelessness have been portrayed as the failure, willing or unwilling, of the individual. From this perspective then, access to income support is reliant on the ability to demonstrate one is deserving of assistance.

\section{Conclusion}

A social and political environment in which it is acceptable for Government to discriminate against (or for) populations based on particular characteristics provides the conditions for justifications for discrimination and disadvantage. Irrespective of the justification or target of discrimination, it establishes a way of thinking that can be applied to suit changing political and economic circumstances. In the same way, a culture in which the prevailing rationality sets self reliance and financial independence as the standard, failure to conform becomes the basis for exclusion. This includes a capacity to delineate between those who may be deemed worthy and those who are not.

This then leads to the question what will be required to reorient the dominant discourse from one of deserving and to one which reflects the explicit and implicit intentions of the international agreements to which Australia proclaims its support. In practical terms this means asking what is wrong with homelessness rather than what is wrong with the homeless.

\section{About the Author}

Dr. Emily Schindeler

With a background in applied research, key interests include human rights as experienced by diverse populations in a wide range of contexts and the nature of discourse and governance which impact on the realization of individual and group rights. 



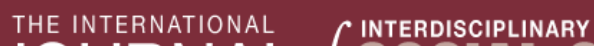 JOURNAL Of SOGHAL SGIENGES}

\section{EDITORS}

Mary Kalantzis, University of Illinois, Urbana-Champaign, USA.

Bill Cope, University of Illinois, Urbana-Champaign, USA.

\section{EDITORIAL ADVISORY BOARD}

Patrick Baert, Cambridge University, Cambridge, UK.

Norma Burgess, Syracuse University, Syracuse, USA.

Bill Cope, University of Illinois, Urbana-Champaign, USA.

Peter Harvey, University of Adelaide, Adelaide, Australia.

Vangelis Intzidis, University of the Aegean, Rhodes, Greece.

Paul James, RMIT University, Melbourne, Australia.

Mary Kalantzis, University of Illinois, Urbana-Champaign, USA.

Gerassimos Kouzelis, University of Athens, Athens, Greece.

Massimo Leone, University of Turin, Turin, Italy.

Alexandros-Andreas Kyrtsis, University of Athens, Athens, Greece.

José Luis Ortega Martín, Universidad de Granada, Granada, Spain.

Bertha Ochieng, University of Bradford, Bradford, UK.

Francisco Fernandez Palomares, Universidad de Granada, Granada, Spain.

Miguel A. Pereyra, Universidad de Granada, Granada, Spain.

Constantine D. Skordoulis, University of Athens, Athens, Greece.

Chad Turnbull, ESADE Business School, Barcelona, Spain.

Chryssi Vitsilakis-Soroniatis, University of the Aegean, Rhodes, Greece.

Please visit the Journal website at http://www.SocialSciences-Journal.com for further information about the Journal or to subscribe. 


\section{THE UNIVERSITY PRESS JOURNALS}

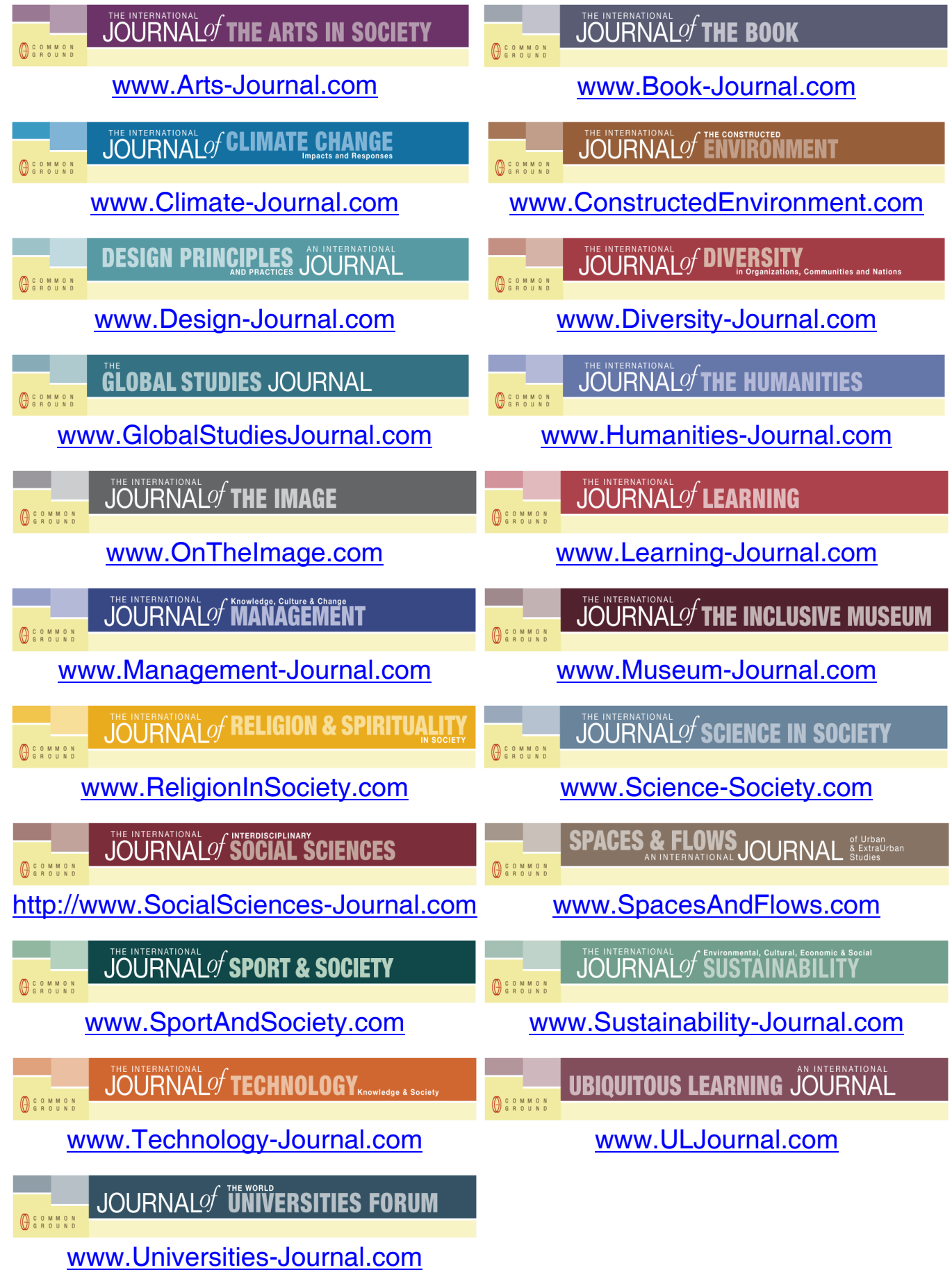

FOR SUBSCRIPTION INFORMATION, PLEASE CONTACT subscriptions@commongroundpublishing.com 